\title{
BMJ Open Use pattern and predictors of use of highly caffeinated energy drinks among South Korean adolescents: a study using the Health Belief Model
}

Dongmun Ha, Inmyung Song, Gyeongil Jang, Eui-Kyung Lee, Ju-Young Shin

To cite: Ha D, Song I, Jang $\mathrm{G}$, et al. Use pattern and predictors of use of highly caffeinated energy drinks among South Korean adolescents: a study using the Health Belief Model. BMJ Open 2017;7:e017224. doi:10.1136/ bmjopen-2017-017224

- Prepublication history for this paper is available online. To view these files please visit the journal online (http://dx.doi org/10.1136/bmjopen-2017017224).

Received 12 April 2017 Revised 11 August 2017 Accepted 31 August 2017

\section{CrossMark}

School of Pharmacy, Sungkyunkwan University, Suwon, Korea

Correspondence to Professor Ju-Young Shin; shin.jy@skku.edu

\section{ABSTRACT}

Objectives Concerns about the use of highly caffeinated energy drinks among Korean adolescents remains. We compared adolescents' perceptions regarding the use of drinks to their behaviours and factors.

Design A structured questionnaire based on the Health Belief Model was administered to 850 freshmen and sophomores at three high schools in Bucheon, South Korea. Benefits were defined as beneficial effects from the use of highly caffeinated energy drinks (eg, awakening from sleepiness) and harms as adverse effects of the drinks (eg, cardiac palpitation). Likelihood of action represents the likelihood of taking actions that are perceived to be more beneficial after comparison of the benefits and harms of caffeine use. Descriptive analysis was used to quantify the relationship between their beliefs about highly caffeinated energy drinks and their use. We conducted hierarchical logistic regression to compute ORs and 95\% Cls for: (1) demographic factors, (2) health threat, (3) likelihood of action and (4) cues to act.

Results Altogether, 833 students responded to the questionnaire (effective response rate $=98.0 \%$ ). About $63.0 \%$ reported use of highly caffeinated energy drinks and $35.2 \%$ had used them as needed and habitually. The more susceptible the respondents perceived themselves to be to the risk of using these drinks, the less likely they were to use them (OR: $0.73,95 \% \mathrm{Cl} 0.50$ to 1.06). The more severe the perception of a health threat, the less that perception was associated with use (OR: $0.44,95 \% \mathrm{Cl} 0.29$ to 0.67$)$. Likelihood of action was the strongest predictor of use, explaining $12.5 \%$ in use. Benefits and harms (OR: $4.43,95 \% \mathrm{Cl} 2.77$ to 7.09 ; OR: $1.86,95 \% \mathrm{Cl} 1.16$ to 2.99 ) also were significant predictors.

Conclusions Enhancing adolescents' perceptions of benefits and harms regarding using highly caffeinated energy drinks could be an effective way to influence the use of these drinks.

\section{INTRODUCTION}

Highly caffeinated energy drinks are often used by surgeons to help address the fatigue caused by long working hours and by students seeking cognitive enhancement. ${ }^{1} 2$ Many adolescents consume highly caffeinated energy drinks, expecting these drinks to

\section{Strengths and limitations of this study}

- This study measured the explanatory power of each factor influencing the consumption of highly caffeinated energy drinks and compared these power levels between factors.

- The relationship between adolescents' beliefs concerning highly caffeinated energy drinks, such as perceived health threat, and likelihood of action, cues to action and current use, was identified using the Health Belief Model.

- The sample used might not be representative of all Korean adolescents across regions and school types.

- Other sources of caffeine intake, such as colas, and measurements of caffeine intake, such as frequency, amount ingested and duration of use, were not considered.

quickly increase their alertness and replenish their levels of mental and physical energy. ${ }^{3-7}$ Caffeine was consumed in the forms of caffeinated drinks, tablets, as well as coffee by German adolescents. ${ }^{8}$ Male students in North America tend to consume these drinks in conjunction with other substances while participating in sports. ${ }^{9}$ High school students in Korea tend to consume these drinks to stay awake while studying for exams in an environment of fierce competition for admission to prestigious colleges. Students in Korea are under extraordinarily high pressure to academically achieve, and this is evidenced by the fact that in 2013 the academic stress index in Korea was found to be $50.5 \%$ higher than the average $(33.3 \%)$ of the 30 countries surveyed. ${ }^{10}$

Caffeine is a methylxanthine that stimulates the central nervous system. It increases alertness and concentration, but excessive caffeine ingestion can result in numerous physical and psychological symptoms, including irritability, anxiety, depression, nervousness, sleep deprivation and headaches. ${ }^{11}$ It also could 
elevate blood pressure and cause dehydration and, in extreme cases, heart attack. ${ }^{12}$ Long-term overconsumption of caffeine can cause stomach ulcers, erosive esophagitis or gastro-oesophageal reflux disease. ${ }^{13}$ The use of caffeinated energy drinks has been associated with symptoms, such as headache, ${ }^{14}$ gastrointestinal problems, ${ }^{15}$ insomnia, ${ }^{16}$ loss of appetite ${ }^{17}$ and anxiety. ${ }^{18}$ Moreover, caffeine can also negatively influence adolescents' development because it can disturb sleep between 23:00 and 2:00, a time when growth hormones are mostly secreted. Also, the oversecretion of peptic acid caused by caffeine intake can cause nausea that might deter the growth and development of very selective eaters. ${ }^{19}$

Users of highly caffeinated energy drinks are likely to experience feelings of depression. ${ }^{20}$ Adolescents' use of highly caffeinated energy drinks has been strongly associated with their concurrent use of alcohol, tobacco and narcotics. ${ }^{21}$ Therefore, overuse of these drinks could negatively influence adolescents' health and behaviour. In 2011, based on the evidence of adverse health effects, the American Academy of Pediatrics recommended adolescents aged 12-18 years old consume no more than $100 \mathrm{mg}$ of caffeine a day. ${ }^{22}$ Nowak et al studied the consumption patterns of energy drinks in Poland (2629 students in junior and senior high schools) by defining overuse as daily consumption of energy drinks, too much use as consuming these drinks a few times a week and much use as consuming these drinks once a week. ${ }^{23}$

The Health Belief Model $(\mathrm{HBM})^{24}$ is a commonly employed theoretical model used to explain the relationship between individuals' beliefs and their behaviours in individual areas of health. ${ }^{25}$ In order to assist decisions concerning the correct actions to adopt to address certain issues, the model advocates considering 'perceived health threat', 'likelihood of action' and 'cue to action'. ${ }^{26}$ Specifically, 'perceived health threat' relates to perceived susceptibility to a particular health problem and the perceived severity of that health problem; 'likelihood of action' is defined as when an individual considers the perceived benefits and barriers associated with certain actions; and 'cue to action' is defined as exposure to commercial advertisements and recommendations from acquaintances that encourage the user to make a behavioural change.

Thus far, little is known about Korean adolescents' patterns of use regarding highly caffeinated energy drinks or the factors associated with such use. Consequently, this study analyses Korean adolescents' perceptions and behaviours regarding highly caffeinated energy drinks, including their awareness of the health impacts, their patterns and reasons for use and the factors associated with their use of such drinks. Specifically, we hypothesise that adolescents' patterns of use of highly caffeinated energy drinks may be determined using the HBM models' aspects of 'perceived health threat', 'likelihood of action' and 'cues to action'.

\section{METHODS}

\section{Study participants}

This study analysed survey data sourced from 850 high students from three high schools based in Bucheon, Korea. To obtain these data, a structured, paper-based questionnaire was distributed to all freshmen and sophomores at the three selected high schools. Each student was asked to complete the questionnaire independently, and then return it to the survey administrator; the students' responses were anonymous. Survey distribution and collection was conducted over 8 days, from 5 April to 13 April 2015. The study protocol was approved by the Sungkyunkwan University Institutional Review Board (IRB No. SKKU-2015-02-004).

\section{Conceptual model and measurement}

To identify the factors associated with the use of highly caffeinated energy drinks, the survey questionnaire used was developed based on the conceptual framework of the HBM. As mentioned above, the HBM comprises three factors: perceived health threat, likelihood of action and cues to action; we decided to allocate two questions to each factor and to use a five-point scale to measure responses.

\section{Perceived health threat: susceptibility and severity}

The decision to measure perceived health threat in the study was based on the premise that individuals choose to adopt certain health behaviours when they believe that their health is threatened. Perceived health threat has two measurable dimensions: perceived susceptibility and perceived severity. In this study, we defined perceived susceptibility as relating to the belief that one is susceptible to health problems, diseases, disabilities and injuries as a result of using highly caffeinated energy drinks, and we defined perceived severity as relating to whether respondents regarded the ill effects of using these drinks, such as death, disability, chronic pain, economic difficulties and damage to family or social relationships, as serious rather than trivial.

\section{Likelihood of action: benefits and harms}

To measure likelihood of action, we based our questions on the assumption that individuals choose to use drinks when they expect the benefits of these drinks to outweigh the drinks' harms. We employed two variables to measure this factor: benefits and harms. Specifically, we defined benefits as the beneficial effects obtained from the use of highly caffeinated energy drinks (eg, increased alertness), and harms as the adverse effects of such drinks (eg, cardiac palpitation). Furthermore, we defined likelihood of action as the likelihood that a user, after comparing the benefits and harms of caffeine use, chooses to continue drinking caffeinated drinks because the consequences are perceived to be more beneficial than harmful. The questions in this regard were only directed towards respondents who reported that they had used these drinks. 
Cues to action: media and the recommendations of family members and friends

Cues to action is defined as strategies used to activate individuals' 'readiness' to engage in certain behaviours. ${ }^{27}$ In regard to this study, the variables in question concerned cues from the media or recommendations from family members or friends to use caffeinated drinks. Specifically, media cues relate to exposure to mass media, such as television, magazines and the internet, which might influence adolescents' beliefs that using highly caffeinated energy drinks is useful for recovery from fatigue and preventing drowsiness. Meanwhile, recommendations from family members or friends were also included in this study because these individuals commonly influence adolescents' behaviours.

\section{Demographic factors}

Age, sex, grade (academic report), extent of stress regarding grades (perceived pressure to academically achieve), the respondent's parents' economic status, health and educational levels and the respondent's previous education on safe drug use were in the model. The respondents were categorised into three groups by grade, stress regarding grades, socioeconomic status and health of parents. For each variable, the average was set based on the respondent's subjective evaluation. The respondent was then asked to select one out of three choices (below average, average or above average). Each parent's educational level was classified as high school degree or less, college degree or graduate degree. Previous education on safe drug use was the number of times the respondent had attended those educational programmes.

\section{The structured questionnaire and coding}

A structured questionnaire was developed based on the conceptual framework of the HBM. Each factor of the HBM consists of two questions. All items except the demographic factors and dependent variable (current use of highly caffeinated energy drinks) were measured on five-point scales where $1=$ strongly disagree, $2=$ disagree, $3=$ neither agree nor disagree, $4=$ agree and $5=$ strongly agree (table 1). The dependent variable measured the current use of highly caffeinated energy drinks where $1=$ currentuse and $0=$ currentnon-use. The independent variables were perceived health threat, likelihood of action, cues to act and the demographic factors as described above.

\section{Statistical analysis}

First, descriptive analysis was performed to identify the characteristics of the respondents. The means and SD were calculated on the variables. Internal consistency was measured using Cronbach's alpha for factors related to adolescents' beliefs (perceived health threat, likelihood of action and cues to act). Second, applying a $2 \times 2$ table, $\chi^{2}$ tests were used to examine the relationship between adolescents' beliefs concerning (positive and negative responses) and current use (whether they were a user or non-user) of highly caffeinated drinks. Lastly, a hierarchical logistic regression analysis was performed to test the relative effects of the independent variables on the

Table 1 Summary of scales, variables, measure values and analysis values

\begin{tabular}{|c|c|c|c|}
\hline Scale (composition) & Variable & Measure value & Analysis value \\
\hline \multirow[t]{4}{*}{ Demographic factors } & Age & Years & Constant \\
\hline & Sex & Male/female & Male $=0$ and female $=1$ \\
\hline & $\begin{array}{l}\text { Parents' education status } \\
\text { (father/mother) }\end{array}$ & $\begin{array}{l}\text { High school degree or less/ } \\
\text { college degree/graduate degree }\end{array}$ & $\begin{array}{l}\text { High school degree or less }=0 \text {, } \\
\text { college degree and graduate } \\
\text { degree }=1\end{array}$ \\
\hline & $\begin{array}{l}\text { Previous health education on } \\
\text { safe drug use }\end{array}$ & Frequencies & $\geq 2$ times $=1$ and $<2$ times $=0$ \\
\hline Perceived health threat & $\begin{array}{l}\text { Perceived susceptibility } \\
\text { Perceived severity }\end{array}$ & 5-point scale† & $\begin{array}{l}4 \text { or } 5 \text { points }=1 \text { (positive) and } \\
\leq 3 \text { points }=0 \text { (negative) }\end{array}$ \\
\hline Cues to act & $\begin{array}{l}\text { Media } \\
\text { Recommendation from family } \\
\text { members or friends }\end{array}$ & 5-point scale† & $\begin{array}{l}4 \text { or } 5 \text { points }=1 \text { (positive) and } \\
\leq 3 \text { points }=0 \text { (negative) }\end{array}$ \\
\hline Caffeine use & $\begin{array}{l}\text { Current use of highly caffeinated } \\
\text { energy drinks }\end{array}$ & 2-point scalef & $\begin{array}{l}\text { Current use }=0 \\
\text { current do not use }=1\end{array}$ \\
\hline
\end{tabular}

${ }^{*}$ More than middle $=3$, middle $=2$ and less than middle $=1$.

†: Strongly agree(5), Agree(4), Undecided(3), Disagree(2) and Strongly disagree(1), ‡: Yes(0) and No(1) 
respondents' use of highly caffeinated energy drinks and to explore the relationships between the independent variables. The parameters of the independent variables predicting the use of highly caffeinated energy drinks were estimated using ORs and 95\% CIs by entering blocks of variables into the model in the following order: (1) demographic factors, (2) perceived health threat, (3) likelihood of action and (4) cues to action; specifically, the stronger the effect a block of variables was expected to have on use, the later it was entered into the model. This order of entry allowed us to estimate the predictive power of each additional variable and block of variables, controlling for the effects of the variables already entered. The explanatory power of the model was identified using Nagelkerke's $R^{2}$. All of the statistical analyses were performed using a SAS statistical application program (V.9.4), and statistical significance was tested at the $\mathrm{p}<0.05$ level.

\section{RESULTS}

The sample comprised 836 students who responded to the questionnaire (response rate: $98.4 \%$ ), and 833 cases were analysed after discarding three cases with missing data (effective response rate: $98.0 \%$ ). The mean age was $16.5 \pm 0.8$ years. The majority was male $(\mathrm{n}=463,55.6 \%)$. Of the 833 respondents, $792(95.1 \%)$ reported that they were aware that the drinks they could buy in stores contained high amounts of caffeine. Five hundred and twenty-five $(63.0 \%)$ reported that they had consumed these drinks and $293(35.2 \%)$ reported consuming the drinks as needed or habitually. More males $(42.6 \%)$ than females (25.1) used highly caffeinated energy drinks. Additionally, most of the respondents' parents had college degrees or lower (fathers $=91.4 \%$, mothers $=94.9 \%$ ). Finally, approximately $40.8 \%$ of the respondents reported that they had received no previous health education on safe drug use (table 2). Cronbach's alpha values were $0.72,0.76$ and 0.71 on perceived health threat, likelihood of action and cues to action, respectively (table 3 ).

\section{Beliefs and behaviours}

The relationships between all of the independent variables (except media cues) and the current use of highly caffeinated energy drinks were found to be statistically significant. Of current users, approximately $27.0 \%$ perceived caffeinated drinks to pose a health threat, while approximately $41.4 \%$ perceived no health threat. Furthermore, approximately $28.5 \%$ of current users perceived a severe health threat, and approximately $54.2 \%$ did not perceive a severe health threat $(p<0.05)$. In fact, more respondents reported perceptions of severity $(n=615)$ than of susceptibility $(\mathrm{n}=359)(\mathrm{p}<0.05)$.

Respondents who reported positively concerning benefits and harms were more likely to be current users than non-users $(62.8 \%$ and $65.1 \%$, respectively) $(\mathrm{p}<0.05)$. Moreover, approximately $36.0 \%$ of the respondents who reported exposure to related media were current users of
Table 2 Demographic characteristics of the sample

\begin{tabular}{ll}
\hline Variable & $\begin{array}{l}\text { Participants, } \\
\text { no. (\%) }\end{array}$ \\
\hline Age (in years), mean (SD) & $16.5(0.8)$ \\
Sex & \\
$\quad$ Female & $370(44.4)$ \\
$\quad$ Male & $463(55.6)$
\end{tabular}

Awareness that energy drinks contain high amounts of caffeine

$\begin{array}{lc}\text { Yes } & 792(95.1) \\ \text { No } & 41(4.9)\end{array}$

Use of caffeinated energy drink

$\begin{array}{ll}\text { Current use* } & 293(35.2) \\ \text { Past use } & 232(27.8) \\ \text { Non-use } & 308(37.0) \\ \text { Grade† } & \\ \text { Below average } & 233(28.0) \\ \text { Average } & 310(37.2) \\ \text { Above average } & 290(34.8) \\ \text { Stress regarding gradesł } & \\ \text { Below average } & 218(26.2) \\ \text { Average } & 375(45.0) \\ \text { Above average } & 240(28.8)\end{array}$

Father's education

$\begin{array}{lc}\text { High school degree or lower } & 307(36.9) \\ \text { College degree } & 454(54.5) \\ \text { Graduate degree } & 72(8.6)\end{array}$

Mother's education

$\begin{array}{lc}\text { High school degree or lower } & 450(54.0) \\ \text { College degree } & 341(40.9) \\ \text { Graduate degree } & 42(5.0)\end{array}$

Parents' socioeconomic status

\begin{tabular}{lc} 
Below average & $206(24.7)$ \\
Average & $419(50.3)$ \\
Above average & $208(25.0)$ \\
Parents' health status & \\
Below average & $377(45.3)$ \\
Average & $376(45.1)$ \\
Above average & $71(9.6)$ \\
Previous health education on safe drug use & $75(9.0)$ \\
More than three times & $260(31.2)$ \\
Two or three times & $158(19.0)$ \\
One time & $340(40.8)$ \\
None & $833(100.0)$ \\
\hline Total &
\end{tabular}

${ }^{*}$ Current use of caffeinated energy drinks as needed or habitually. †Academic reports.

‡Pressure felt to academically achieve. 
Table 3 Descriptive statistics of perceived health threat, likelihood of action and cues to act with Cronbach's alphas

\begin{tabular}{llll}
\hline Variable & Mean & SD & $\begin{array}{l}\text { Cronbach's } \\
\text { alpha }\end{array}$ \\
\hline $\begin{array}{l}\text { Perceived health threat } \\
\quad\end{array}$ & 3.96 & 0.84 & 0.72 \\
$\quad \begin{array}{l}\text { Susceptibility } \\
\quad \text { Severity }\end{array}$ & 3.24 & 1.02 & \\
$\begin{array}{l}\text { Likelihood of actiont } \\
\quad \text { Benefits }\end{array}$ & 3.75 & 0.43 & 0.76 \\
$\quad$ Harms & 1.20 & 0.43 & \\
$\begin{array}{l}\text { Cues to actł } \\
\quad \text { Media }\end{array}$ & 3.63 & 0.96 & 0.71 \\
$\quad \begin{array}{l}\text { Recommendations of } \\
\text { family members or friends }\end{array}$ & 2.23 & 1.03 & \\
\hline
\end{tabular}

*Adolescents' perception of their susceptibility and that the health threat of caffeinated drinks is serious.

†Adolescents' perception of the expected benefits or harms of using highly caffeinated energy drinks.

$\ddagger$ The effect of suggestions from media or recommendations from family members or friends on adolescents' motivation to consume highly caffeinated energy drinks. these drinks, while $33.7 \%$ reported experiencing no such exposure; furthermore, the coefficient was non-significant. Lastly, respondents who received recommendations from family members or friends $(48.5 \%)$ were more likely to be current users than those who did not receive such recommendations $(33.3 \%, \mathrm{p}<0.05)$ (table 4$)$.

\section{Factors associated with using highly caffeinated energy drinks}

In the hierarchical logistic regression analysis, the four groups of factors were found to all significantly contribute to the use of highly caffeinated energy drinks. The demographic factors (model 1) explained approximately $1.5 \%$ of the variance in use $(\mathrm{p}<0.05)$; however, none of the subsequent variables of the demographic factors were found to be significant (table 5). Perceived health threat, which was added in model 2, explained an additional $5.5 \%(\mathrm{p}<0.05)$ of the variance; the more severe the perceived health threat, the less it was associated with current use (OR: $0.44,95 \%$ CI 0.29 to 0.67 ), and the more susceptible the respondent felt to a perceived health threat, the less it was associated with current use

Table 4 Positive and negative responses to questions concerning perceived health threat, likelihood of action and cues to action and their effect on current use and non-use of highly caffeinated energy drinks

\begin{tabular}{|c|c|c|c|c|c|c|}
\hline Category & Variables & Response & $\begin{array}{l}\text { Current use } \\
\text { No. (\%) }\end{array}$ & $\begin{array}{l}\text { Non-use } \\
\text { No. (\%) }\end{array}$ & $\begin{array}{l}\text { Total } \\
\text { No. (\%) }\end{array}$ & p Value \\
\hline \multirow{6}{*}{$\begin{array}{l}\text { Perceived health } \\
\text { threat }^{*}\end{array}$} & \multirow[t]{3}{*}{ Susceptibility† } & Positive & $97(27.0)$ & $262(73.0)$ & $359(100.0)$ & \multirow[t]{3}{*}{$<0.001 \ddagger$} \\
\hline & & Negative & $196(41.4)$ & $278(58.6)$ & $474(100.0)$ & \\
\hline & & Total & $293(35.2)$ & $540(64.8)$ & $833(100.0)$ & \\
\hline & \multirow[t]{3}{*}{ Severity† } & Positive & $175(28.5)$ & $440(71.5)$ & $615(100.0)$ & \multirow[t]{3}{*}{$<0.001$} \\
\hline & & Negative & $117(54.2)$ & $99(45.8)$ & $216(100.0)$ & \\
\hline & & Total & $292(35.1)$ & $539(64.9)$ & $831(100.0)$ & \\
\hline \multirow[t]{6}{*}{ Likelihood of action§ } & \multirow[t]{3}{*}{ Benefits $\dagger$} & Positive & $251(62.8)$ & $149(37.3)$ & $400(100.0)$ & \multirow[t]{3}{*}{$<0.001 \ddagger$} \\
\hline & & Negative & $41(31.3)$ & $90(68.7)$ & $131(100.0)$ & \\
\hline & & Total & $292(55.0)$ & $239(45.0)$ & $531(100.0)$ & \\
\hline & \multirow[t]{3}{*}{ Harms† } & Positive & $82(65.1)$ & $44(34.9)$ & $126(100.0)$ & \multirow[t]{3}{*}{$0.010 \ddagger$} \\
\hline & & Negative & $211(51.8)$ & $196(48.2)$ & $407(100.0)$ & \\
\hline & & Total & $293(55.0)$ & $240(45.0)$ & $533(100.0)$ & \\
\hline \multirow[t]{6}{*}{ Cues to actionๆ } & \multirow[t]{3}{*}{ Media† } & Positive & $193(36.0)$ & $343(64.0)$ & $536(100.0)$ & \multirow[t]{3}{*}{0.496} \\
\hline & & Negative & $100(33.7)$ & $197(66.3)$ & $297(100.0)$ & \\
\hline & & Total & $293(35.2)$ & $540(64.8)$ & $833(100.0)$ & \\
\hline & \multirow{3}{*}{$\begin{array}{l}\text { Recommendations } \\
\text { from family members } \\
\text { or friends } \dagger\end{array}$} & Positive & $49(48.5)$ & $52(51.5)$ & $101(100.0)$ & \multirow[t]{3}{*}{$0.004 \dagger$} \\
\hline & & Negative & $244(33.3)$ & $488(66.7)$ & $732(100.0)$ & \\
\hline & & Total & $293(35.2)$ & $540(64.8)$ & $833(100.0)$ & \\
\hline
\end{tabular}

*Perceptions of susceptibility and that the health threat of caffeinated drinks is serious.

†Positive: agree or strongly agree; negative: neither agree nor slightly disagree, disagree or strongly disagree.

‡Statistically significant.

§Perceptions of the expected benefits or harms of using highly caffeinated energy drinks.

१The effect of suggestions from media or recommendations from family members or friends on motivation to consume highly caffeinated energy drinks. 
Table 5 Results of the hierarchical logistic regression analysis

\begin{tabular}{|c|c|c|c|c|}
\hline & Step 1 & Step 2 & Step 3 & Step 4 \\
\hline Variables & OR $(95 \% \mathrm{Cl})$ & OR $(95 \% \mathrm{Cl})$ & OR $(95 \% \mathrm{Cl})$ & OR $(95 \% \mathrm{Cl})$ \\
\hline \multicolumn{5}{|l|}{ Demographic characteristics } \\
\hline Age & 1.01 (0.81 to 1.26$)$ & 1.01 (0.81 to 1.27$)$ & 0.96 (0.76 to 1.21$)$ & 0.97 (0.76 to 1.22$)$ \\
\hline Sex & 1.38 (0.96 to 2.01$)$ & 1.23 (0.84 to 1.79$)$ & 1.47 (0.98 to 2.21$)$ & 1.49 (0.99 to 2.24) \\
\hline Grade & 1.01 (0.69 to 1.46$)$ & 1.00 (0.68 to 1.47$)$ & 0.85 (0.57 to 1.28$)$ & $0.86(0.57$ to 1.30$)$ \\
\hline Father's education & 1.19 (0.77 to 1.83$)$ & 1.11 (0.71 to 1.72$)$ & 1.09 (0.69 to 1.75$)$ & 1.07 (0.67 to 1.72$)$ \\
\hline Mother's education & 0.90 (0.59 to 1.37$)$ & 0.90 (0.58 to 1.38$)$ & 0.89 (0.56 to 1.41$)$ & 0.90 (0.57 to 1.43$)$ \\
\hline Stress about grades & $1.08(0.73$ to 1.60$)$ & $1.11(0.74$ to 1.66$)$ & 0.98 (0.64 to 1.51$)$ & 0.98 (0.64 to 1.51$)$ \\
\hline Parents' health status & 0.86 (0.46 to 1.61$)$ & $0.90(0.48$ to 1.71$)$ & 1.03 (0.53 to 2.00$)$ & 0.99 (0.51 to 1.95$)$ \\
\hline Parents' economic status & 0.96 (0.61 to 1.52$)$ & $0.96(0.60$ to 1.53$)$ & 0.96 (0.58 to 1.57$)$ & 0.96 (0.58 to 1.59$)$ \\
\hline Pre-education of medicine & 0.82 (0.58 to 1.18$)$ & 0.92 (0.64 to 1.33$)$ & 0.89 (0.60 to 1.32$)$ & 0.89 (0.60 to 1.32$)$ \\
\hline \multicolumn{5}{|l|}{ Perceived health threat* } \\
\hline Susceptibility & & $0.73(0.50$ to 1.06$)$ & $0.62 \dagger(0.41$ to 0.94$)$ & $0.62 \dagger(0.41$ to 0.94$)$ \\
\hline Severity & & $0.44 \dagger(0.29$ to 0.67$)$ & $0.41 \dagger(0.26$ to 0.64$)$ & $0.40 \dagger(0.25$ to 0.62$)$ \\
\hline \multicolumn{5}{|l|}{ Likelihood of action $\ddagger$} \\
\hline Benefits & & & $4.43 \dagger(2.77$ to 7.09$)$ & $4.32 \dagger(2.69$ to 6.92$)$ \\
\hline Harms & & & $1.86 \dagger(1.16$ to 2.99$)$ & $1.78+(1.10$ to 2.86$)$ \\
\hline \multicolumn{5}{|l|}{ Cues to act§ } \\
\hline Media & & & & 1.36 (0.91 to 2.05$)$ \\
\hline $\begin{array}{l}\text { Recommendations from family } \\
\text { members or friends }\end{array}$ & & & & 1.22 (0.68 to 2.17$)$ \\
\hline \multicolumn{5}{|l|}{ Model summary } \\
\hline $\mathrm{Na} \mathrm{R}^{2}$ & $0.015 \dagger$ & $0.070 \dagger$ & $0.195 \dagger$ & $0.202 \dagger$ \\
\hline$\Delta R^{2}$ & - & $0.055 \dagger$ & $0.125 \dagger$ & $0.007 \dagger$ \\
\hline
\end{tabular}

${ }^{*}$ Perceptions of susceptibility and that the health threat of caffeinated drinks is serious. †Statistically significant.

‡Perceptions of the expected benefits or harms of using highly caffeinated energy drinks.

$\S$ The effect of suggestions from media or recommendations from family members or friends on motivation to consume highly caffeinated energy drinks.

$\mathrm{Na}$, Nagelkerke.

(OR: $0.73,95 \%$ CI 0.50 to 1.06 ). Likelihood of action had the strongest effect, adding $12.5 \%(\mathrm{p}<0.05)$ to the overall explanatory power of the model; specifically, the more cognizant respondents were of benefits (OR: 4.43, $95 \% \mathrm{CI} 2.77$ to 7.09$)$ and harms (OR=1.86, 95\% CI 1.16 to 2.99), the more likely they were to be current users of these drinks. Lastly, cues to action added $0.7 \%(\mathrm{p}<0.05)$ to the explanatory power, and all of the factors combined explained $20.2 \%$ of the variance; however, media and recommendations of family members or friends were not statistically significant (table 5).

\section{DISCUSSION}

This study analysed Korean adolescents' beliefs and behaviours regarding the use of highly caffeinated energy drinks and investigated the factors associated with their use of these drinks, such as perceived health threat, likelihood of action and cues to action. The respondents' perceptions of benefits and harms regarding threats to health as a result of using these drinks were the strongest predictors of current use, explaining $12.5 \%$ of the variance in current use; furthermore, those who perceived benefits were 4.43 times more likely to be current users of these drinks, while those who perceived harms were 1.86 times more likely. These findings imply that the more cognizant an individual is of the benefits and harms of energy drinks, the more likely they are to consume these drinks. It is natural that knowledge of benefits is associated with a greater use of highly caffeinated energy drinks; however, it is probable that the positive association between the recognition of harms and the use of these drinks represents a case of a reverse causal relationship: in other words, high consumers of these drinks have greater knowledge of their harms. 
Of the 833 respondents, $792(95.1 \%)$ reported that they were aware that the highly caffeinated energy drinks sold in stores contained high amounts of caffeine. Five hundred and twenty-five $(63.0 \%)$ respondents reported that they had consumed these drinks and $293(35.2 \%)$ consumed the drinks as needed or habitually. This finding is consistent with a study on Canadian high school students in 2012 that found that $62 \%$ of the students had consumed the drinks at least once during the previous year and $40 \%$ of them had done so at least once per month. ${ }^{28}$ Similarly, $94 \%$ of German adolescents were aware of energy drinks and $53 \%$ of them had sampled these drinks. ${ }^{22}$ More German students reported to have used caffeinated drinks than caffeine tablets for the purpose of cognitive enhancement. ${ }^{8}$ Energy drinks were consumed by $67 \%$ of Polish adolescents, and $58 \%$ of Switzerland adolescents were occasional users or regular users. ${ }^{23} 29$ There are a number of motives for using energy drinks: insufficient sleep, to increase energy while studying, driving long periods, drinking alcohol and to treat a hangover. ${ }^{30}$

In the current study's analysis, users of highly caffeinated drinks were found to be more likely than non-users to perceive the severity of risk as below average and were also more likely than non-users to perceive the likelihood of risk occurrence as below average. According to a 2011 online survey of adolescents conducted by the Centers for Disease Control and Prevention, ${ }^{31}$ those who use highly caffeinated energy drinks more than once per week are 7.7 times more likely than non-users to perceive these drinks as safe. These findings suggest that raising adolescents' awareness of the severity of risk concerning and their susceptibility to engaging in caffeine overconsumption might reduce the number of users.

This study also found that, among respondents who currently used energy drinks, perceived knowledge of benefits and harms significantly influenced use status. The odds of current use were greater in respondents with higher perceived benefits and harms, while perceptions of expected benefits or harms as a result of using these drinks were the strongest predictors of current use.

More males than females use highly caffeinated energy drinks. In Canada, studies have found that the use of energy drinks is consistently more common among male than female students. ${ }^{32} 33$ Similarly, the number of boys who consumed these drinks every day has been found to be 2-2.3 times the number of girls who do so in North America and Europe, ${ }^{34}$ Iceland $^{35}$ and Finland. ${ }^{36}$ This finding suggests that the gender distribution of users of highly caffeinated energy drinks is similar across countries and that health-education programmes should focus on raising awareness of perceived susceptibility among male students. However, aside from gender, current use has not been found to be associated with sociodemographic factors, academic grades, pressure to academically perform, parents' educations, parents' socioeconomic and health statuses or previous health education. Additionally, while it was found that students who received recommendations from family members or friends tended to consume these drinks, exposure to media was not associated with current use.

The importance of health education regarding the judicious use of highly caffeinated energy drinks has been highlighted by Sherwood. ${ }^{37}$ Furthermore, as the current study found that using these drinks is influenced by recommendations from family members and friends, it is clear that the implementation of guidance in school and family settings is required.

The severe consequences of adolescents developing caffeine addiction relate to the fact that caffeine addiction is associated with health and welfare problems such as severe stress, chronic depression and overall poor health status. ${ }^{38}$ The US poison centres collect information on the adverse health effects of highly caffeinated energy drinks. ${ }^{39} 40$ However, Korea does not have a system of collecting and analysing such data to apply to health education and inform policymaking. Therefore, scientific evidence is lacking on the numbers of students experiencing health risks by using energy drinks or the longterm health effects. More research is needed to produce evidence on the effects of caffeine on adolescent health.

This study identified the relationship between adolescents' beliefs concerning highly caffeinated energy drinks, such as perceived health threat, likelihood of action, cues to action and current use. Through a hierarchical logistic regression model, factors associated with adolescents' use of highly caffeinated energy drinks were identified, and recommendations for changing their behaviours were derived. Despite its strengths, however, the findings of this study might not be generalisable because of the following limitations: first, the sample might not be representative of all Korean adolescents. High-school seniors (third graders in the South Korean high school system) were excluded from our study because we expected a low response rate from students at this level; however, these should have been included in order to investigate their patterns of use of caffeinated drinks to enhance academic performance; this is important because these students experience the heaviest pressure to academically achieve. Thus, in order to increase representativeness, future research should survey all students.

Another limitation arose by not including students across regions and school types. In this study, we surveyed students from three preparatory schools located within a single city; however, generalisability would have been improved if the study had included students from rural areas and all school types (preparatory, vocational and special purpose schools). Furthermore, other sources of caffeine intake, such as colas, and measurements of caffeine intake, such as frequency, amount ingested and duration of use, were not considered in this study. This makes it difficult to compare our findings with those of other studies, because differences exist in terms of definitions of caffeine use and evaluation criteria (eg, daily consumption, once-a-week consumption and frequency of consumption in the last month). 


\section{CONCLUSIONS}

This study analysed South Korean adolescents' beliefs and behaviours regarding the use of highly caffeinated energy drinks and the factors associated with their use. Despite the stated limitations, this study's findings can help future research on adolescent health behaviours generate scientific evidence that supports the preparation of behaviour modification plans. To build on these findings, future research should investigate in detail adolescents' behaviours considering caffeine intake and dietary habits, as well as factors that influence adolescents' behavioural changes and motivations.

Contributors DH and J-YS designed the study and research concept. GJ acquired and arranged the data. Analysis and interpretation of data were performed by $\mathrm{E}-\mathrm{KL}$ and IS. DH, IS and J-YS prepared the manuscript. All authors contributed to the drafting of the paper and approved the final submitted version. The authors of this manuscript take responsibility for the integrity of the data and the accuracy of the data analysis.

Competing interests None declared.

Patient consent Obtained.

Ethics approval The Sungkyunkwan University Institutional Review Board.

Provenance and peer review Not commissioned; externally peer reviewed.

Open Access This is an Open Access article distributed in accordance with the Creative Commons Attribution Non Commercial (CC BY-NC 4.0) license, which permits others to distribute, remix, adapt, build upon this work non-commercially, and license their derivative works on different terms, provided the original work is properly cited and the use is non-commercial. See: http://creativecommons.org/ licenses/by-nc/4.0/

(c) Article author(s) (or their employer(s) unless otherwise stated in the text of the article) 2017. All rights reserved. No commercial use is permitted unless otherwise expressly granted.

\section{REFERENCES}

1. Franke AG, Bagusat C, McFarlane C, et al. The use of caffeinated substances by surgeons for Cognitive enhancement. Ann Surg 2015;261:1091-5.

2. Dietz P, Soyka M, Franke AG. Pharmacological neuroenhancement in the field of economics-Poll results from an online survey. Front Psychol 2016;7.

3. Arria AM, O'Brien MC. The "high" risk of energy drinks. JAMA 2011;305:600-1.

4. Babu KM, Church RJ, Lewander W. Energy drinks: The new eyeopener for adolescents. Clin Pediatr Emerg Med 2008;9:35-42.

5. Oddy WH, O'Sullivan TA. Energy drinks for children and adolescents. BMJ 2009;339:b5268.

6. Reissig CJ, Strain EC, Griffiths RR. Caffeinated energy drinks-a growing problem. Drug Alcohol Depend 2009;99:1-10.

7. Smit HJ, Cotton JR, Hughes SC, et al. Mood and cognitive performance effects of "energy" drink constituents: caffeine, glucose and carbonation. Nutr Neurosci 2004;7:127-39.

8. Franke A, Christmann M, Bonertz C, et al. Use of coffee, caffeinated drinks and caffeine tablets for cognitive enhancement in pupils and students in Germany. Pharmacopsychiatry 2011;44:331-8.

9. Buxton C, Hagan JE. A survey of energy drinks consumption practices among student -athletes in Ghana: lessons for developing health education intervention programmes. J Int Soc Sports Nutr 2012:9.

10. The Korea Institute for Health and Social Affairs. The subjective wellbeing of Korean children and its policy implications. 2015.

11. Rath M. Energy drinks: what is all the hype? the dangers of energy drink consumption. J Am Acad Nurse Pract 2012;24:70-6.

12. Rottlaender D, Motloch LJ, Reda S, et al. Cardiac arrest due to long QT syndrome associated with excessive consumption of energy drinks. Int J Cardiol 2012;158:e51-e52.

13. Ding M, Bhupathiraju SN, Satija A, et al. Long-term coffee consumption and risk of cardiovascular disease: a systematic review and a dose-response meta-analysis of prospective cohort studies. Circulation 2014;129:643-59.

14. Hering-Hanit R, Gadoth N. Caffeine-induced headache in children and adolescents. Cephalalgia 2003;23:332-5.

15. Casuccio A, Bonanno V, Catalano R, et al. Knowledge, attitudes, and practices on energy drink consumption and side effects in a cohort of medical students. Journal Addict Dis 2015;34:274-83.

16. Nordt SP, Claudius I, Rangan C, et al. Reasons for energy drink use and reported adverse effects among adolescent emergency department patients. Pediatr Emerg Care 2016:1.

17. Miller JW, Naimi TS, Brewer RD, et al. Binge drinking and associated health risk behaviors among high school students. Pediatrics 2007;119:76-85.

18. Hedges DW, Woon FL, Hoopes SP. Caffeine-induced psychosis. CNS Spectr 2009;14:127-31.

19. Guilbeau JR. Health risks of energy drinks: What nurses and consumers need to know. Nurs Women's Health 2012;16:423-8.

20. Richards G, Smith AP. A review of energy drinks and mental health, with a focus on stress, anxiety, and depression. $J$ Caffeine Res 2016;6:49-63.

21. Terry-McElrath YM, O’Malley PM, Johnston LD. Energy drinks, soft drinks, and substance use among United States secondary school students. J Addict Med 2014;8:6-13.

22. Seifert SM, Schaechter JL, Hershorin ER, et al. Health effects of energy drinks on children, adolescents, and young adults. Pediatrics 2011;127:511-28.

23. Nowak D, Jasionowski A. Analysis of the consumption of caffeinated energy drinks among Polish adolescents. Int J Environ Res Public Health 2015;12:7910-21.

24. Colombo G, et al. Moderate and severe plaque psoriasis: Cost-ofillness study in Italy. Ther Clin Risk Manag 2008;4:559-68.

25. Villar OAE-D, Montañez-Alvarado $P$, Gutiérrez-Vega M, et al. Factor structure and internal reliability of an exercise health belief model scale in a Mexican population. BMC Public Health 2017:17:229.

26. Glanz K, Lewis FM, Rimer BK, eds. Health behavior and health education. 3rd edn. San Francisco: Jossey-Bass, 2002.

27. Ha D, Song I, Park S, et al. Factors associated with the management of adverse drug reactions among community pharmacists in South Korea. J Patient Saf 2015:1. Epub ahead of print.

28. Azagba S, Langille $D$, Asbridge $M$. An emerging adolescent health risk: Caffeinated energy drink consumption patterns among high school students. Prev Med 2014;62:54-9.

29. Barrense-Dias $Y$, Berchtold A, Akre C, et al. Consuming energy drinks at the age of 14 predicted legal and illegal substance use at 16. Acta Paediatr 2016;105:1361-8.

30. Malinauskas BM, Aeby VG, Overton RF, et al. A survey of energy drink consumption patterns among college students. Nutr $J$ 2007;6:35

31. Kumar G, Park S, Onufrak S. Perceptions about energy drinks are associated with energy drink intake among U.S. youth. American J Health Promotion 2015;29:238-44.

32. Reid JL, Hammond D, McCrory C, et al. Use of caffeinated energy drinks among secondary school students in Ontario: Prevalence and correlates of using energy drinks and mixing with alcohol. Can J Public Health 2015;106:e101-8.

33. Reid JL, McCrory C, White CM, et al. Consumption of caffeinated energy drinks among youth and young adults in Canada. Prev Med Rep 2017;5:65-70.

34. Visram S, Cheetham M, Riby DM, et al. Consumption of energy drinks by children and young people: a rapid review examining evidence of physical effects and consumer attitudes. BMJ Open 2016;6:e010380

35. Kristjansson AL, Sigfusdottir ID, Mann MJ, et al. Caffeinated sugarsweetened beverages and common physical complaints in Icelandic children aged 10-12 years. Prev Med 2013.

36. Huhtinen H, Rimpelä A, Lindfors P. Adolescents' use of energy drinks and caffeine. Eur J Public Health 2013;23.

37. Sherwood J. Energy drinks: Beverage industry response. CMAJ 2010;182:1647-8.

38. Rockett I. Caffeine "addiction" in high school youth: Evidence of an adverse health relationship. Addict Res Theory 2002;10:31-42.

39. Greenwald PW, Farmer BM, O'Neill M, et al. Increasing frequency and fatality of poison control center reported exposures involving medication and multiple substances: data from reports of the American Association of Poison Control Centers 1984-2013. Clin Toxicol 2016;54:590-6.

40. Mowry JB, Spyker DA, Brooks DE, et al. Annual Report of the American Association of Poison Control Centers' National Poison Data System (NPDS): 32nd Annual Report. Clin Toxicol 2014;2015;53:962-1147. 